\title{
The determination of the folic acid and its selected derivatives
}

\author{
Barbara Krawczyk*, Dominik Szczukocki, Justyna Stachniuk, Radosław Dałkowski, Marek Zieliński, \\ Renata Juszczak, Ewa Miękoś and Robert Zakrzewski
}

The University of Lodz, Department of Inorganic and Analytical Chemistry, Laboratory of Environmental Threats, 91-403 Lodz, Tamka 12, Poland

\begin{abstract}
Folic acid (FA) belongs to vitamins from group B. The most commonly used drug from a group of structural analogues of FA is methotrexate (MTX), showing antiproliferatative properties. Unfortunately, the action of MTX is not selective. Toxic effects of methotrexate may be partially abolished by the use of leucovorin (calcium salt of folinic acid, FNA) in conserving therapy. The aim of the presented paper was to develop a new analytical procedure using the capillary electrophoresis, allowing the separation and the quantitative marking of the folic acid, methotrexate and calcium salt of folinic acid. Optimal conditions for the electrophoretic separation were obtained for the following parameters: buffer - $25 \mathrm{mmol} / \mathrm{L} \mathrm{Na}_{2} \mathrm{~B}_{4} \mathrm{O}_{7}, \mathrm{pH} 9,76$; voltage $-30 \mathrm{kV}$, measurement temperature $-30{ }^{\circ} \mathrm{C}$, the introduction of a sample to the capillary hydrodynamically $6 \mathrm{~s}(0,5 \mathrm{psi})$. These parameters allowed to obtain LOD 0,6 $\mu \mathrm{M}$ for FA, 0,65 $\mu \mathrm{M}$ for FNA and $0,7 \mu \mathrm{M}$ for MTX.
\end{abstract}

Keywords: electrophoresis; folic acid; methotrexate; folinic acid.

\section{Introduction}

Folic acid (FA), methotrexate (MTX) and folinic acid (FNA) may be included to the pteridine derivatives. Pteridines are a class of heterocyclic chemical compounds, commonly occurring in living organisms. Some of them play a role of bio-pigments, while others act as cofactors in biochemical transformations important for the proper functioning of the body. One of the best known pteridine derivatives with a broad spectrum of effect is the folic acid. FA after conversion in the presence of dihydrofolate reductase (DHFR) to the biologically active form acts as the carrier of active one-carbon groups needed in the biosynthesis of methionine or purine and pyrimidine bases. This step is blocked in the presence of competitive antagonists FA (antimetabolites) such as methotrexate or aminopterin ${ }^{1}$. These compounds, thanks to the huge structural similarity to the natural metabolite or coenzyme, inhibit or disrupt competitively the process of a specific metabolic pathway by taking the active place in the target enzyme or incorporation, instead of metabolite, in place of the construction unit, necessary for the proper functioning of the cell ${ }^{2}$. Consequently, there is often conducted the treatment of cancer using the so-called combined therapy using the structural analogue FA - folinic acid ${ }^{2}$. Accordingly, it is particularly important to monitor the

* Corresponding author: Barbara Krawczyk

E-mail address: b.t.krawczyk@gmail.com

DOI: http://dx.doi.org/10.13171/mjc.3.4.2014.09.24.12.29 
concentration of folinic acid, methotrexate and the folic acid, among others, in pharmaceutical preparations or body fluids (urine, blood, cerebrospinalfluid).

Huge interest in the marking of folic acid, methotrexate and folinic acid in samples of diverse origin results from their numerous applications among others in such fields like medicine, food industry or pharmaceuticals. Following reports of the literature one can find many articles describing the methods of marking the folic acid and its structural analogues using numerous separation techniques, among which the special place is occupied by the high performance liquid chromatography (HPLC) and less common, but enjoying now increasing popularity, capillary electrophoresis (CE). These techniques were applied among others in the analysis of pharmaceutical preparations, containing methotrexate, conducted in order to determine the content of the biologically active enantiomer responsible for its effectiveness ${ }^{3-5}$. Moreover, they are used in the analysis of dietary supplements with necessary for the proper functioning of the body, vitamins from group $\mathrm{B}^{6}$ and diverse in terms of the qualitative composition of food products, with particular emphasis on the marking of contents of FA used for food enrichment ${ }^{8-10}$. Another important example of using HPLC and CE is the use of these separation techniques for therapeutic drugs monitoring (TDM) and their metabolites in body fluids. As TDM constitutes an important area of research, which goal is to adjust the individual doses for each patient, in order to obtain the optimal response of the body and to avoid undesirable side effects. HPLC and CE are perfectly suitable for routine analyses in diagnostic laboratories, as they fulfil four basic features of the ideal separation technique, such as speed, high resolution, low costs and simplicity of analysis ${ }^{11}$. A number of advantages which characterise the high performance liquid chromatography and capillary electrophoresis made them also find use in the diagnosis and treatment of cancers realised through marking the contents of methotrexate, folic and folinic acid and products of their metabolic changes in biological samples ${ }^{12-17}$.

Marking the contents of FA, FNA, MTX and products of their metabolic changes in body fluids using electromigration techniques is most often accomplished using the capillary zone electropheresis $(\mathrm{CZE})^{14-15}$ as well as more rarely used micellar electro-kinetic chromatography $(\mathrm{MEKC})^{16-17}$. In general the electrophoretic analysis is conducted in the alkaline environment $^{14-15}$ using, as the basic electrolite, the aqueous phosphate buffer solution ${ }^{14,16,17}$, samples are dispensed automatically, with hydrodynamic method and the analytical signal is registered using the spectrophotometric detector UV/Vis (Table 1).

The aim of the presented paper was to develop a new analytical procedure allowing the separation of the mixture containing folic acid, methotrexate and calcium salt of folinic acid, and their quantitative determination using the capillary electrophoresis with the detector DAD. The developed CE method has the potential of practical use in the analysis of urine samples, as it enables the qualitative and quantitative determination of MTX, FNA, FA in less than 20 minutes 
Table 1. The conditions of the electrophoretic analysis of biological samples containing folic acid, folinic acid, methotrexate and products of their metabolic changes.

\begin{tabular}{|c|c|c|c|c|}
\hline $\begin{array}{c}\text { Marker } \\
\text { compound }\end{array}$ & CE type & Conditions of electrophoretic analysis & Comment & Literature \\
\hline $\begin{array}{l}\text { FA, FNA, } \\
\text { MTX }\end{array}$ & CZE & $\begin{array}{l}\text { Capillary: } 50 \mathrm{~cm} / 60,2 \mathrm{~cm} \text { x } 75 \mu \mathrm{m} \text { I.D. } \\
\text { Buffer: } 15 \mathrm{mM} \text { phosphate } \mathrm{pH} 12,0 \\
\text { Detection: } 305 \mathrm{~nm} \text { (DAD) } \\
\mathrm{U}: 25 \mathrm{kV} \\
\mathrm{T}: 20^{\circ} \mathrm{C} \\
\text { Hydrodynamic introduction of the sample } \\
7 \mathrm{~s}(0,5 \mathrm{psi})\end{array}$ & $\begin{array}{l}\text { Sample: urine } \\
\text { Preparation of the sample for } \\
\text { analysis: SPE } \\
\text { LOD: } 0,8 \mu \mathrm{M} \text { (FA, FNA, MTX) } \\
\text { Linearity: } \\
\text { MTX } 2,2-132 \mu \mathrm{M} \text {, } \\
\text { FNA; FA } 1-12 \mu \mathrm{M}\end{array}$ & 14 \\
\hline $\begin{array}{l}\text { MTX } \\
\text { 7-OHMTX } \\
\text { DAMPA } \\
\text { MTX - }(\mathrm{PG})_{\mathrm{n}} \\
\mathrm{n}=2-7\end{array}$ & CZE & $\begin{array}{l}\text { Capillary: } 30 \mathrm{~cm} / 40,2 \mathrm{~cm} \text { x } 50 \mu \mathrm{m} \text { I.D. } \\
\text { Buffer: } 1,2 \mathrm{M} \text { glycine } \mathrm{pH} 9,3 \\
\text { Detection: } 300 \mathrm{~nm} \text { (DAD) } \\
\mathrm{U}: 20 \mathrm{kV} \\
\mathrm{T}: 25^{\circ} \mathrm{C} \\
\text { Hydrodynamic introduction of the sample } \\
5 \mathrm{~s}(0,5 \mathrm{psi})\end{array}$ & $\begin{array}{l}\text { Sample: blood } \\
\text { Preparation of the sample for } \\
\text { analysis: deproteinisation, LLE } \\
\text { LOD:1 } \mu \mathrm{M} \text { (MTX, 7-OHMTX, MTX } \\
\left.-\mathrm{PG}_{2-4}\right) \\
3 \mu \mathrm{M}\left(\mathrm{MTX}_{-} \mathrm{PG}_{5-6}\right), 5 \mu \mathrm{M}(\mathrm{MTX}- \\
\left.\mathrm{PG}_{7}\right) \text {, } \\
8 \mu \mathrm{M} \text { (DAMPA) } \\
\text { Internal standard: protriptyline }\end{array}$ & 15 \\
\hline $\begin{array}{l}\text { MTX } \\
\text { 7-OHMTX } \\
\text { DAMPA } \\
\text { MTX - }(\mathrm{PG})_{\mathrm{n}} \\
\mathrm{n}=2-7\end{array}$ & MECK & $\begin{array}{l}\text { Capillary: } 40 \mathrm{~cm} / 50,2 \mathrm{~cm} \text { x } 50 \mu \mathrm{m} \text { I.D. } \\
\text { Basic buffer: } 80 \mathrm{mM} \mathrm{NaH}{ }_{2} \mathrm{PO}_{4} \mathrm{pH} 2,5 \\
\left(\mathrm{H}_{3} \mathrm{PO}_{4}\right) ; 100 \mathrm{mM} \text { SDS, } \\
15 \% \text { THF (v/v) } \\
\text { Buffer HCB: } 100 \mathrm{mMNaH}_{2} \mathrm{PO}_{4} \mathrm{pH} 2,5 \\
\left(\mathrm{H}_{3} \mathrm{PO}_{4}\right) \\
\text { Detection:300 nm (UV/Vis) } \\
\mathrm{U}: 20 \mathrm{kV} \\
\mathrm{T}: 25^{\circ} \mathrm{C} \\
\text { Hydrodynamic introduction of the } \\
\text { sample200 } \mathrm{s}(1 \mathrm{psi}), \mathrm{HCB} 60 \mathrm{~s}(1 \mathrm{psi})\end{array}$ & $\begin{array}{l}\text { Sample: blood } \\
\text { Preparation of the sample for } \\
\text { analysis: deproteinisation, SPE } \\
\text { LOD:0,1 } \mu \mathrm{M} \text { (MTX); 0,2 } \mu \mathrm{M}(7- \\
\text { OHMTX, DAMPA) } \\
0,3 \mu \mathrm{M}\left(\mathrm{MTX}_{-} \mathrm{PG}_{2-5}\right) ; 0,5 \mu \mathrm{M} \\
\left(\mathrm{MTX}-\mathrm{PG}_{6-7}\right) \\
\text { Internal standard: } 2,4 \text {-hexadienoic }\end{array}$ & 16 \\
\hline
\end{tabular}

Where: 7-OHMTX 7-hydroxymethotrexate, DAMPA 2,4-diamino-N-methylopterine acid, MTX - PG derivatives of polylutamatemethotrexate

\section{Experimental Section}

During the tests there was used the apparatus for capillary electrophoresis Agilent 7100 (Agilent Technologies, USA) equipped with the detector DAD (Agilent Technologies, USA). The system was connected to the computer with software ChemStation Data Analysis, enabling the operation and maintenance of all sub-systems of the apparatus for CE, registration and analysis of measurement results. For the separation there was used the silica capillary $(72 \mathrm{~cm} / 80,5 \mathrm{~cm} \times 75 \mu \mathrm{m}$ I.D, Agilent Technologies, USA), which was washed with $0,1 \mathrm{~mol} / \mathrm{L} \mathrm{NaOH}$ (15 min), then with deionised water (10 min) and supporting electrolyte (10 $\mathrm{min})$. Between successive measurements, in order to obtain reproducibility, the capillary was conditioned by rinsing with $0,1 \mathrm{~mol} / \mathrm{L} \mathrm{NaOH}(60 \mathrm{~s})$, then with deionised water $(60 \mathrm{~s})$ and the buffer for analysis (180 s). All activities connected with the introduction of the sample to the capillary took place automatically, with the hydrodynamic method. 
In the tests there were used the following reagents: folic acid, methotrexate, calcium salt of folinic acid (TCI, Japan), sodium tetraborate (POCH, Poland), sodium carbonate (POCH, Poland), sodium hydroxide (purity HPCE, Merck, Germany) and the deionised water (HLP Spring HydroLab System, Poland). Standard solutions were prepared on the measurement day, and soaked before the use by the $0,2 \mu$ m nylon membrane.

\section{Results and Discussion}

An extremely important element in the development of new analytic procedure is the determination of optimal separationconditions of components of the analysed sample. During the studies, special attention was paid to the ensuring of the best possible separation of the components of the sample in a relatively short time and to obtain the high precision and as low as possible detection limits.

In order to determine the analytical wavelength, there was registered the spectrum of the tested mixture of compounds, containing FA, FNA i MTX, in the range from UV to the close IR $(190 \mathrm{~nm}$ to $950 \mathrm{~nm})$. Based on the analysis of the obtained spectrum of the tested mixture of compounds, as the optimal wavelength $(\lambda)$ was selected $280 \mathrm{~nm}$, which was used in further electrophoretic measurements.

To find optimal conditions of the electrophoretic separation of mixture containing folic acid, methotrexate and calcium salt of folinic acid, there was tested the influence of a number of parameters. These include the concentration and $\mathrm{pH}$ of the buffer for the analysis, capillary temperature $(\mathrm{T})$, applied voltage $(\mathrm{U})$ or the time of the sample introduction to the capillary, on the effectiveness of the separation process and the time of analysis. The assessment criteria of electrophoretic analyses were the time $(\mathrm{t})$ of migration of the marked substances, height and surface area (A) of the obtained analytical signals.

\section{Determination of the optimal concentration of the buffer for analysis}

During the selection of the suitable buffer for CE analyses, there was most of all considered the acidic character of the marked compounds and stability of FA in the alkaline environment ${ }^{19}$. Therefore, in all electrophoretic analyses, as a separation medium there was used the solution of sodium tetraborate with buffering properties within the range of $\mathrm{pH}$ $8,2-10,2^{18}$. A very important parameter significantly influencing the quality of the electrophoretic analysis is the buffer concentration. Therefore, there was prepared a series of buffer solutions with concentrations from the range of $10 \mathrm{mmol} / \mathrm{L}-35 \mathrm{mmol} / \mathrm{L}$, which $\mathrm{pH}$ was approximately 9,26. Results obtained during the experiments were summarised in the form of migration time of marked compounds in the function of the buffer concentration (Figure 1). 


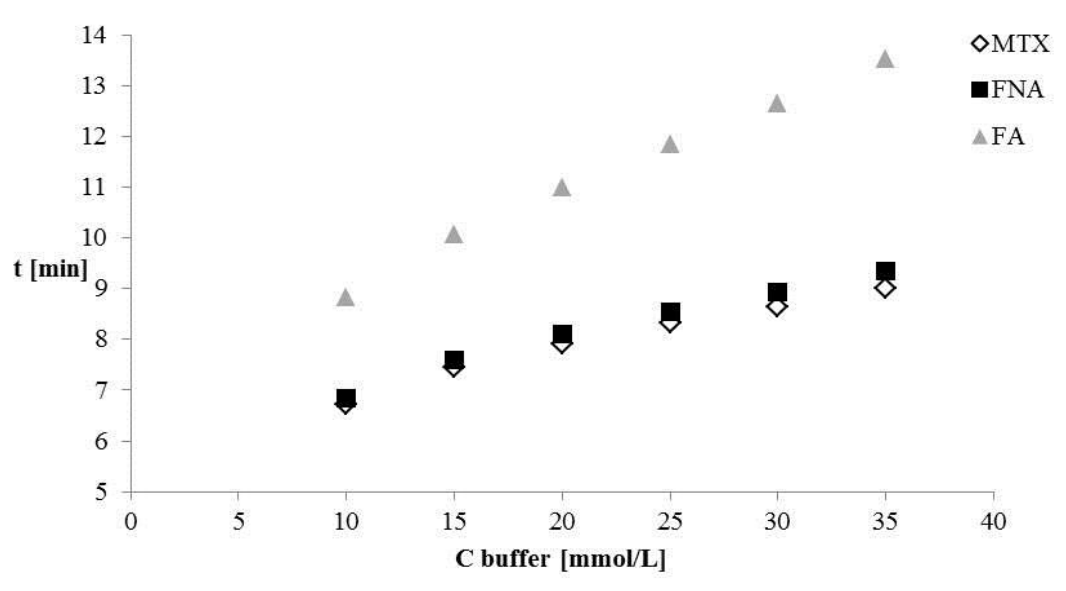

Figure 1.The dependence of the migration time of the marked compounds in the function of the buffer concentration.

From the analysis of dependencies presented in Figure 1 it results that with the increase of the concentration of the tetraborate buffer, the marked compounds migrate slower, and the migration time shows the almost linear upward trend. The observed prolongation of the analysis time with the increasing concentration of the tetraborate buffer, could result from the reduction of the rate of the electroosmotic flow (EOF) caused by the decrease of the zeta potential on the internal surface of the capillary walls. Moreover, it was observed that with the increase of the buffer concentration the decrease of the electrophoretic separation caused by the emitting Joule heat took place. Accordingly, the optimal concentration of the buffer solution, enabling the satisfactory separation of the marked compounds in the relatively short time and with the good quality of the obtained analytical signals, there was accepted $25 \mathrm{mmol} / \mathrm{L}$, which was used in further studies.

\section{The selection of $\mathrm{pH}$ of the buffer for analysis}

Another tested parameter during the procedure of optimization of $\mathrm{CE}$ conditions was the $\mathrm{pH}$ of the buffer solution selected for the electrophoretic analysis. $\mathrm{pH}$ has a huge influence both on the level of ionisation of silanol groups on the capillary walls and the electrophoretic mobility of the studied substances. Given the acidic nature of the marked compounds and knowing the particular constants of dissociation for each of them ${ }^{20}$ it was accepted that the compounds over pH 6,1 are completely dissociated and are found only in the form of anions. Therefore, there was tested the influence of $\mathrm{pH}$ of the buffer for analysis on the migration time of the components of the studied mixture and their resolution. For this purpose there was prepared the series of buffer solutions with the concentration of $\mathrm{Na}_{2} \mathrm{~B}_{4} \mathrm{O}_{7}$ of $25 \mathrm{mmol} / \mathrm{L}$ and $\mathrm{pH}$ in the rangefrom 9,26 to 10,26 . The obtained results are presented in figure 2 .

In such conditions of the CE analysis, the studied compounds migrate in the following order: MTX, FNA, FA. As shown in Figure 2, with the increase of pH values from 9,26 to 10,26 the resolution between methotrexate and folinic acid, which was the critical parameter, increased and the quality of the obtained analytical signals was improved. However, it was accompanied by the decrease of the electrophoretic mobility of the marked compounds, and thus the prolongation of the analysis time. 


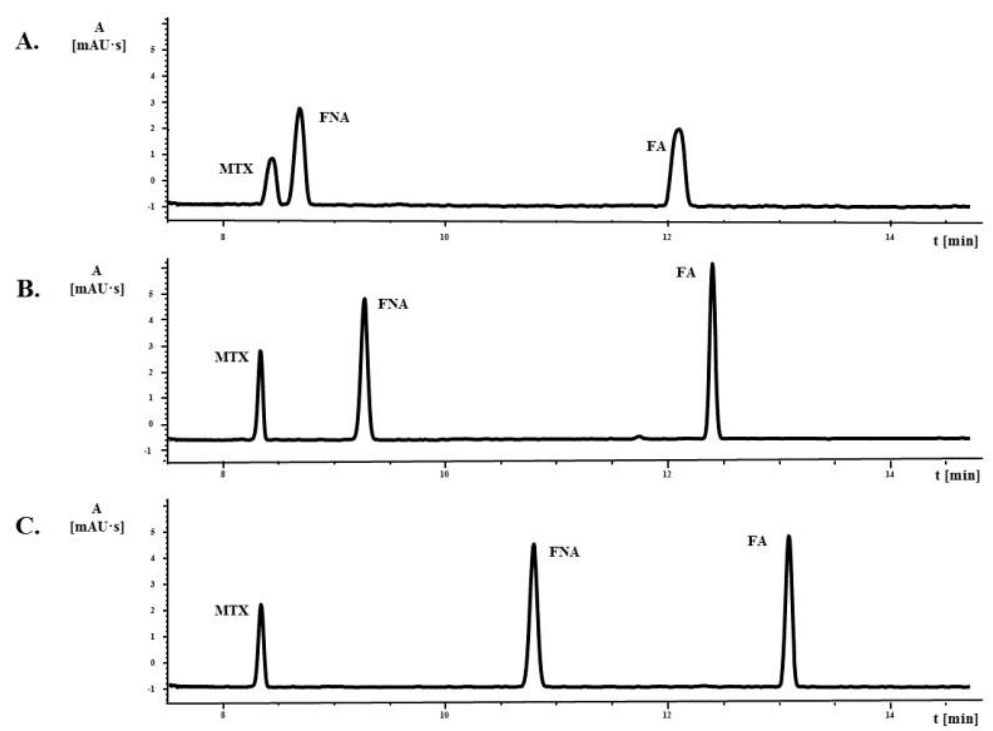

Figure 2. Electrophoregrams of the standard mixture of the studied compounds with the concentration of $10 \mu \mathrm{g} / \mathrm{mL}$ presenting the dependence of the migration time of the marked compounds and their resolution in the function of the buffer $\mathrm{pH}(\mathbf{A}) 9,26 ;(\mathbf{B}) 9,76 ;(\mathbf{C}) 10,26$.

Furthermore, over $\mathrm{pH} 10,26$ there was observed the worsening of the quality of the obtained analytical signals and the broadening of registered peaks. Accordingly, for further studies there was selected thetetraborate buffer $25 \mathrm{mmol} / \mathrm{L}$ with $\mathrm{pH}$ equal 9,76. This enabled the conduction of $\mathrm{CE}$ analyses in conditions providing the satisfactory separation of the marked substances in a relatively short time.

\section{The influence of the applied voltage}

There was also examined the effect of the applied voltage, in the range from $5 \mathrm{kV}$ to 30 $\mathrm{kV}$, on the time of the electrophoretic analysis and the quality of the obtained analytical signals (Figure 3).

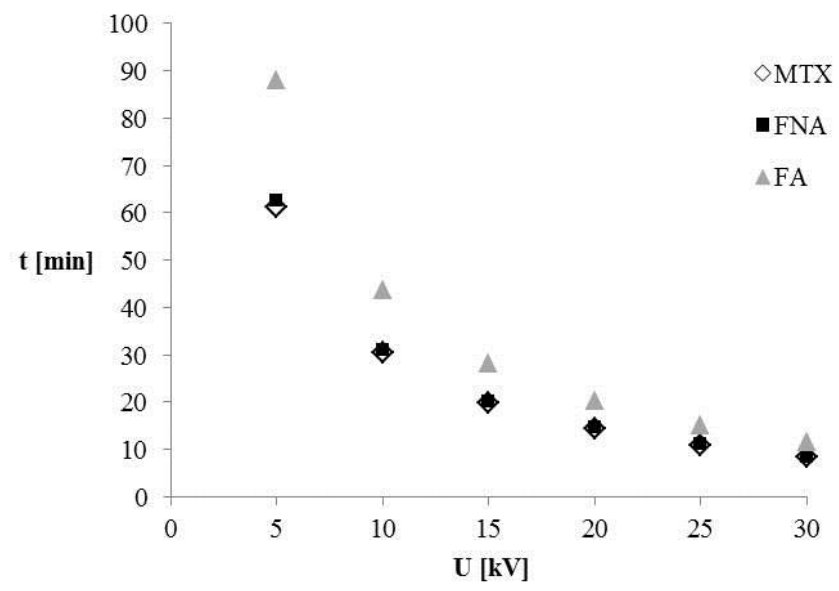

Figure 3. Dependency of the migration time of the marked compounds in the function of the applied voltage.

Both the size of electroosmotic flow and the electrophoretic mobility of the particles are directly proportional to the size of the applied electric field. As expected, with the increase of the applied voltage to the capillary ends, molecules migrated faster and the analysis time was shortened (Figure 3). 


\section{Determination of the optimal capillary temperature}

Controlling the capillarytemperature plays a very important role in $\mathrm{CE}$, as its changes may cause alterations in the efficiency of the electrophoretic separation, viscosity of the buffer used, migration times of the marked compounds, volume of the introduced sample to the capillary and sensitivity of the detector response. In the presented paper there was tested the influence of the capillary temperature within temperature range from $20^{\circ} \mathrm{C}$ to $40^{\circ} \mathrm{C}$ on the separation and migration times of the marked compounds. The obtained results summarised in Table 2 showed that with the increase of the measurement temperature migration times of compounds decreased, what may result directly from the change of the viscosity of the medium. Given the time of analysis and the resolution between the components of the sample, the optimal temperature used in further studies was $30^{\circ} \mathrm{C}$.

Table 2. Migration times of the marked compounds in the function of the capillary temperature.

\begin{tabular}{|c|c|c|c|c|c|}
\hline $\mathbf{T}\left[{ }^{\circ} \mathbf{C}\right]$ & \multirow[b]{2}{*}{20} & \multirow[b]{2}{*}{25} & \multirow[b]{2}{*}{30} & \multirow[b]{2}{*}{35} & \multirow[b]{2}{*}{40} \\
\hline Compound & & & & & \\
\hline MTX & 9,94 & 8,89 & 7,91 & 7,19 & 6,53 \\
\hline FNA & 10,11 & 9,06 & 8,08 & 7,38 & 6,72 \\
\hline FA & 13,77 & 12,29 & 10,98 & 9,94 & 9,01 \\
\hline
\end{tabular}

\section{Influence of time of sample introduction to capillary}

In order to increase the sensitivity of the method and to obtain the lowest possible levels of detection of the analysed compounds, there was examined the influence of sample introduction time to capillary within the range from $3 \mathrm{~s}$ to $6 \mathrm{~s}$. On the basis of the obtained results it was stated that with the given pressure 50 mbar $(0,5 \mathrm{psi})$ optimal results were obtained during the introduction of the sample to capillary automatically, with the hydrodynamic method for $6 \mathrm{~s}$.

\section{Calibration and validation of the developed method}

Validation of the developed method of the determination of the folic acid, methotrexate and folinic acid was conducted taking into account the following validation parametres ${ }^{21}$ : selectivity, linearity, detection and quantification limits, accuracy and precision (repeatability).

In order to perform calibration curves of the standard mixture of the examined compounds there was prepared the series of solutionsof methotrexate, folic acid and calcium salt of folinic acid in concentrations from $0,23 \mu \mathrm{M}$ to $230 \mu \mathrm{M}$. Appropriate concentrations of standard solutions were obtained by performing the series of dilutions of the analytes mixture with the concentration of $2,3 \mathrm{mM}$. For each sample there were conducted three independent markings, performing measurements in the optimised conditions. The obtained analytical results (areas of the peaks) were evaluated statistically. Analytical signals obtained during the analysis were characterised by a good symmetry and satisfactory resolution, based on what there can be stated the selectivity of the developed analytical procedure.

In order to determine the accuracy and precision of the method connected with the random errors and determining the scatter of results around the average value, there were calculated the values of the standard deviation (SD) and the relative standard deviation (RSD). Additionally, using the $\mathrm{t}$-Student test there were marked confidence intervals ( $\Delta \mathrm{x}$ śr, for $\alpha=0,05 ; \mathrm{f}=\mathrm{n}-1$ ). 
In order to determine the linearity of the developed analytical methods, in the tested concentrations range $(0,23-230 \mu \mathrm{M})$, there were calculated values of regression coefficients. In addition, there was determined the significance of the values of coefficients of calibration curve equations by comparison of the calculated parameters of t-Student test (tobl) with critical values ( $\mathrm{t}_{\mathrm{k} r}$, for $\left.\alpha=0,05, \mathrm{f}=\mathrm{n}-2\right)$.

In order to determine the methodsensitivity there were determined the values of detection limits (LOD) and quantification (LOQ), for each of the determined compounds, defined respectively as the smallest concentration of the substance which can be detected/marked using the given analytical procedure with the predetermined precision. In calculations it was assumed that LOD constitutes the triple value of the signal to the noise ratio $(\mathrm{N})$ $(\mathrm{LOD}=3 \mathrm{~S} / \mathrm{N})$, while LOQ the triple value of LOD $(\mathrm{LOQ}=3 \mathrm{LOD})$.

In the studied concentrations range $0,8-230 \mu \mathrm{M}$ the obtained dependencies of the analytical signal on the proportionally changing values of concentration showed the linear nature, as the values of correlation coefficients $\left(\mathrm{R}^{2}\right)$ for calibration curves were at least 0,999 (Fig. 4). On this basis it can be concluded about the possibility to use the developed method for the qualitative and quantitative marking of the studied compounds. The additional confirmation of this thesis are the relative deviation values, which do not exceed $5 \%$ for the highest concentrations prepared in order to draw the calibration curves and $10 \%$ for concentrations corresponding to the lower limits of the quantification.

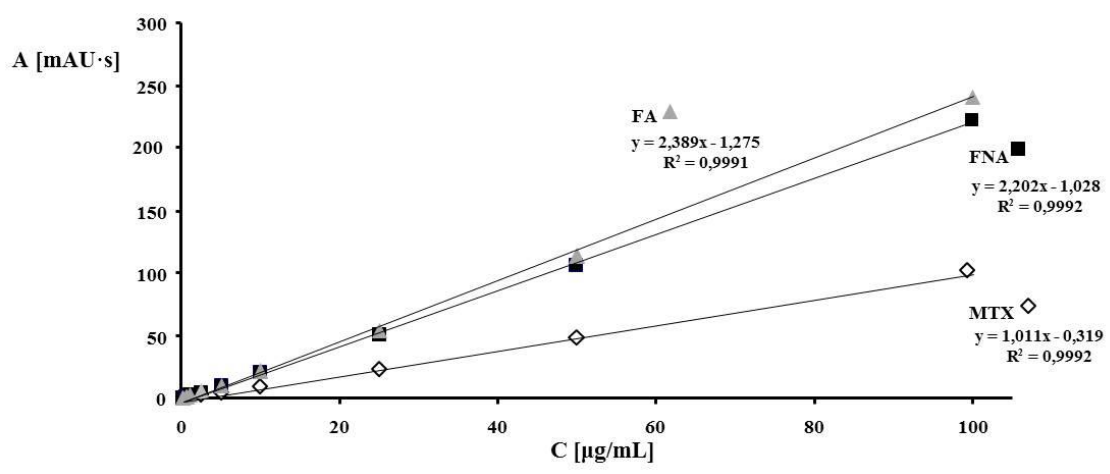

Figure 4. Calibration curves of the standard mixture of studied compounds containing MTX, FNA and FA; made on the basis of peak areas. Electrophoretic conditions: capillary $72 \mathrm{~cm} / 80,5$ cm x $75 \mu \mathrm{m}$ I.D., buffer $25 \mathrm{mmol} / \mathrm{L} \mathrm{Na}_{2} \mathrm{~B}_{4} \mathrm{O}_{7}, \mathrm{pH} 9,76$, voltage $30 \mathrm{kV}$, the introduction of the sample to the capillary hydrodynamically $6 \mathrm{~s}(0,5 \mathrm{psi})$, measurement temperature $30^{\circ} \mathrm{C}, \lambda=280 \mathrm{~nm}$.

\section{The use of the developed $\mathrm{CE}$ method in the analysis of urine samples}

The study undertook the initial attempts to confirm the potential usefulness of the developed electrophoretic method for the separation of FA, FNA and MTX in real samples. For this purpose there was analysed, in optimal conditions of the CE analysis, the urine sample. This urine was previously inoculated with a mixture of studied compounds with a concentration of $113 \mu \mathrm{M}$ and filtered using syringe filters with $0,2 \mu \mathrm{m}$ membrane. 


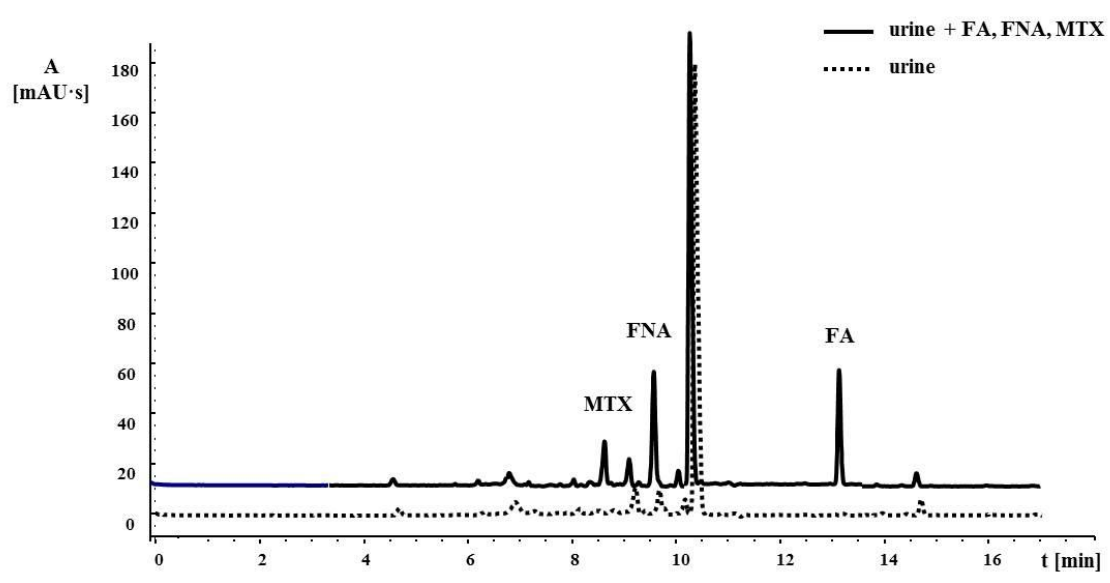

Figure 5. Examples of electrophoregrams obtained for the urine sample inoculated with the mixture of studied compounds in concentration of $113 \mu \mathrm{M}$ (electrophoretic conditions as in figure 4).

Based on preliminary test results, presented in figure 5, it can be stated that the obtained analytical signals of the tested compounds are characterised by a satisfactory resolution and symmetry, and the matrix does not contain endogenous substances, which could cause interference. One can conclude about the potential practical use of the developed CE method.

\section{Conclusions}

This paper presented the optimisation of conditions of the electrophoretic separation enabling the separation of the components of the mixture containing folic acid, methotrexate and calcium salt of folinic acid, which resulted in the development of a new analytical procedure. The optimal conditions for the electrophoretic separation are as follows: silica capillary $72 \mathrm{~cm} / 80,5 \mathrm{~cm}$ x $75 \mu \mathrm{m}$ I.D., buffer $25 \mathrm{mmol} / \mathrm{L} \mathrm{Na} 2 \mathrm{~B}_{4} \mathrm{O}_{7}, \mathrm{pH} 9,76$, detection $280 \mathrm{~nm}$ (DAD), voltage $30 \mathrm{kV}$, measurement temperature $30^{\circ} \mathrm{C}$, the introduction of the sample to the capillary hydro-dynamically $6 \mathrm{~s}(0,5 \mathrm{psi})$. The developed separation method is characterised by high precision, accuracy, specificity and wide ranges of linearity $(0,8-230 \mu \mathrm{M})$. The determined limits of detection for each of the studied compounds are, respectively: FA $-0,6$, FNA $-0,65$ and for MTX $0,7 \mu \mathrm{M}$. Comparison of the described method with the literature data shown in Tabel 3.

Table 3. Comparison of the described method with the literature data.

\begin{tabular}{|l|l|c|l|}
\hline Method in literature & $\mathrm{LOD} \mu \mathrm{M}$ & analysis time [min] & linearity \\
\hline$[14]$ & 0,8 & 10 & $\mathrm{R} \geq 0,9986$ \\
\hline$[15]$ & $1-8$ & 20 & $\mathrm{R} \geq 0,9930$ \\
\hline$[16]$ & $0,1-0,5$ & 30 & $\mathrm{R} \geq 0,9914$ \\
\hline described method & $0,6-0,7$ & 20 & $\mathrm{R} \geq 0,9995$ \\
\hline
\end{tabular}

\section{References}

1- Z. Szakács and B. Noszál, Electrophoresis, 2006, 27, 2299- 3409.

2- K. Orzechowska-Juzwenko, In Farmakologia. Podstawy farmakopeii: Leki przeciwnowotworowe, ed. by W. Kostowski and Z. Herman, Wydawnictwo Lekarskie PZWL: Warszawa,2008, $400-444$. 
3- C.Y. Kuo, H.L. Wu, and S.M. Wu, Anal. Chim.Acta, 2002,471, 211-217.

4- M.M. Huang, L. Penn, J. Bongers and S. Burman, J. Chromatogr. A, 1998, 828, 303 - 309.

5- D.A. El-Hady, N.A. El-Maali, R. Gotti, C. Bertucci, F. Mancini and V.Andrisano, J. Pharm. Biomed. Anal., 2005, 37, 919 - 925.

6- L. Fotsing, M. Fillet, I. Bechet, P. Hubert and J.Crommen, J. Pharm. Biomed. Anal., 1997, 15, 1113-1123.

7- D.B. Gomi, L.L. González and D.G. Álvarez, Anal. Chim.Acta, 1999, 396, 55 - 60.

8- R.H.F. Cheung, P.D. Morrison, D.M. Small andP.J. Marriott, J. Chromatogr. A, 2008, 1213, 93-99.

9 - R.H.F. Cheung, J.G. Hughes, P.J. Marriott and D.M. Small, Food Chem., 2009, 112, 507-514.

10- U.D. Uysal, E.M. Oncu - Kaya and M. Tuncel, Chromatographia, 2010,71, 653 - 658.

11- Z.K. Shihabi, J. Chromatogr. A, 1998, 807, 27-36.

12- K. Michail and M.S. Moneeb, J. Pharm. Biomed. Anal., 2011, 55, 317 - 324.

13- Z. Zhu, H. Wu, S. Wu, Z. Huang, Y. Zhu and L. Xi, J. Chromatogr. A, 2013, 1283, $62-67$.

14- J. Rodríguez Flores, G. Castañeda Peñalvo, A. Espinosa Mansilla and M.J. Rodríguez Gómez, J. Chromatogr. B, 2005,819, 141-147.

15- C.Y. Kuo, H.L. Wu, H.S. Kou, S.S. Chiou, D.C. Wu and S.M. Wu, J. Chromatogr. A, 2003, 1014, 93-101.

16- H.L. Cheng, Y.M. Liao, S.S. Chiou, S.M. Wu, Electrophoresis, 2008,29, 3665 - 3673.

17- H.L. Cheng, S.S. Chiou, Y.M. Liao, C.Y. Lu, Y.L. Chen and S.M. Wu, Anal. Bioanal. Chem., 2010, 398, 2183-2190.

18- Z. Witkiewicz andJ. Kałużna - Czaplińska, Podstawy chromatografii i technik elektromigracyjnych, Wydawnictwo Naukowo - Techniczne: Warszawa,2013.

19- J. Arcotand, A.Shrestha, Trends Food Sci. Tech., 2005, 16, 253-266.

20- N. Şanli, S. Şanli and G. Alsancak, J. Chem. Eng. Data, 2010, 55, 2695-2699.

21- ed. by P. Konieczka and J. Namieśnik Ocena i kontrola jakości wyników pomiarów analitycznych, Wydawnictwo Naukowo - Techniczne: Warszawa, 2007. 